Proceedings of the 2012 Winter Simulation Conference

C. Laroque, J. Himmelspach, R. Pasupathy, O. Rose, and A.M. Uhrmacher, eds

\title{
SIMULATION OF A GREEN WAFER FAB FEATURING SOLAR PHOTOVOLTAIC TECHNOLOGY AND STORAGE SYSTEM
}

\author{
Leann Sanders \\ Stephanie Lopez \\ Greg Guzman \\ Jesus Jimenez \\ Tongdan Jin \\ Ingram School of Engineering, Texas State University \\ San Marcos, TX 78666, USA
}

\begin{abstract}
A semiconductor wafer fab requires a significant amount of energy to maintain its daily operations. Solar photovoltaics (PV) is a clean and renewable technology that can be potentially used to power large wafer fabs. There exist some critical factors slowing the proliferation of facilities powered by PVs, including high capital costs and power output intermittency. This study investigates the reliability and the costs of operating a PV-based distributed generation (DG) system to generate renewable energy for wafer fabs. In addition to PVs, the DG system also features storage devices and a net metering function. We developed a simulation model to mimic the PV generation and load variability. The goal is to design a reliable and cost-effective PV-based DG system to mitigate carbon emissions. Two case studies are presented in this paper to demonstrate the performance of the proposed DG system for fabs located in Austin Texas, USA, and Dresden, Germany.
\end{abstract}

\section{INTRODUCTION}

A modern wafer fabrication facility (fab) consumes on average about $348,905 \mathrm{kWh} /$ day, which is equivalent to powering 10,000 homes (Hu and Chuah 2003; Texas Instruments 2010). The impact of energy consumption on climate change and the rising cost of energy have become a challenging issue facing the semiconductor manufacturing industry today. The International Technology Roadmap for Semiconductors, Environmental, Safety and Health Chapter, raised this concern and urges the critical need for reducing the carbon footprint through designing and deploying green and sustainable manufacturing facilities (ITRS 2011).

Most sustainability practices that are under consideration focus on the reduction of power consumption in wafer fabs. These practices include using standby/idle modes in vacuum pumps, lowering airflow in cleanrooms, and optimizing the heat removal, among others. According to a study conducted by International SEMATECH Manufacturing Initiative (ISMI), the chip manufacturing industry would realize a total savings of $4.8 \times 10^{9} \mathrm{kWh} /$ year, which is approximate to $\$ 480$ million, if these practices for energy reduction were to be implemented appropriately (ISMI 2005).

An alternative approach to green manufacturing is the direct integration of renewable energy in the wafer fabrication process. Currently, only a few chip manufacturers, such as TI, have taken initiatives to make their fabs "greener" by installing solar photovoltaic (PV) panels (Texas Instruments 2010). Generating electricity at the customer site is a new energy production paradigm referred to as Distributed Generation (DG). The DG units that are used for the generation of electricity are called distributed energy resources (DER) which include solar PV panels, wind turbines (WT), and fuel cells, among others. The 


\section{Sanders, Lopez, Guzman, Jin, and Jimenez}

capacity of a DER unit ranges from $3 \mathrm{~kW}$ to $10 \mathrm{MW}$ (Jones and Chowdhury 2008). WT and solar PV technologies are quite appealing because they harness renewable power for electricity generation, leading to zero carbon footprint. However, the output of WT and solar PV is quite intermittent as the power is correlated with wind speed, weather conditions, geographical locations, and seasons of the year. In addition, WT and PV systems are capital-intensive, and the costs for installation and maintenance must be taken into account during the planning of a DG system.

This paper proposes a conceptual framework to power wafer fabs using PV-based DG technology. In particular, the DG system features PV panels, battery banks, and a substation for electricity cogeneration. A simulation model is developed to aid the decision on PV capacity, battery size, and the substation power to meet the hourly electricity loading of a virtual wafer fab. The purpose of the simulation is to mimic the stochastic behavior of the fab loading and the PV generation, and further estimate the loss of load probability (LOLP), $\alpha$. This LOLP represents the chance that the DG generation is lower than the load, leading to the potential outages. The value of $\alpha$ should be very small because any power outage in wafer fabs causes staggering production losses. In addition, the simulation model is capable of measuring the amount of the carbon emissions reduced as the result of the PV penetration.

Villarreal et al. (2012) develops a stochastic model to design DG systems for a single and large industrial user, such as a wafer fab. The DG system studied by Villarreal et al. (2012) consists of wind turbines, PV panels, a net metering system, and a grid-connected substation. Taboada et al. (2012) derived a lifecycle cost model that incorporates the system installation, operations \& maintenance, utility bills, revenues, and carbon taxes. To the best of our knowledge, studies and modeling approaches of DG systems applied to large industry consumers are not available in the literature. This study extends the work in Villarreal et al. (2012) and Taboada et al. (2012) in two main aspects. First, we incorporate the energy storage devices in the DG system, which is expected to further decrease the LOLP. Second, we incorporate the utility provider's dynamic pricing policy, namely the Time-of-Use (TOU) policy, that comprises the peak and the off-peak rates (Ton et al. 2008). With dual rates, new opportunities are created for using the energy storage system to haul and store electricity when the utility rates are lower. The cost function featuring dynamic pricing is expected to be a more accurate way to represent real-world applications.

The remainder of this paper is organized as follows. Section 2 models a virtual wafer fab operated under the distributed generation paradigm. The components of the DG system are introduced. Section 3 formulates a mathematical model to estimate the total DG costs that include the installation, the maintenance and operation, and the utility bills. Section 4 describes the experimental design methodology and analyzes the results. Section 5 concludes the paper with some comments on future work.

\section{SYSTEM DESCRIPTION}

\subsection{Simulation Configuration}

The DG system under study is depicted in Figure 1. The proposed DG system comprises solar PV panels, an energy storage system, a net metering module, and a substation inter-connected with the utility grid. As resources that generate clean and renewable energy, PV panels have the higher priority in supplying the electricity to the wafer fab. If the PV power is insufficient, additional electricity can be hauled from the substation or the battery system to fill the gap. On the other hand, if the PV output exceeds the load, surplus energy is either stored in the battery or fed into the utility grid if the battery is full.

A simulation model based on Matlab codes is developed to simulate the power generation and the load variability of the proposed the DG system described in Figure 1. This model evaluates, on an hourly basis over the duration of 20 years, the energy consumed by the virtual wafer fab and the power provided by the PV system and the substation. It also mimics the electricity charging and discharging activities of the battery system taking into account the dual utility rates in daytime and night. It then computes the DG system's annual costs, the LOLP performance, and the carbon quantity that is avoided due to the PV technology. 


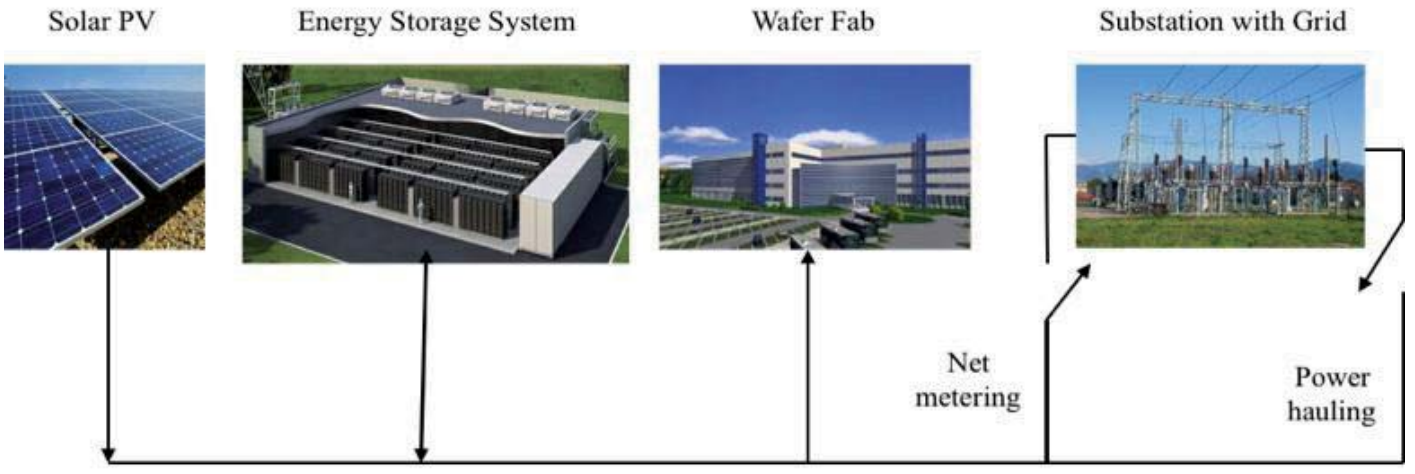

Figure 1: Grid-connected DG system comprising renewable power and storage devices.

\subsection{Modeling PV Power Generation}

In order to simulate the system configuration described in Section 2.1, an analytical model estimating the energy output of the solar PV system is presented below. The premise of this modeling approach is that, given the fixed panel area, the power output of a solar PV system is determined by the panel orientation, the geographical location, the calendar date, the clock time, and the weather condition. Under the clear sky condition, the DC (direct current) power of the PV panel can be expressed as the function of solar radiation as follows (Villarreal et al. 2012):

$$
P_{s}=\eta_{s} A_{s} I_{t}\left(1-0.005\left(T_{o}-25\right)\right),
$$

where, $\eta_{s}$ is the solar PV conversion efficiency (typically between 10-15\%). $A_{s}$ is the panel area, and $T_{o}$ is the PV operating temperature. $I_{t}$ is the solar radiation incident on the PV panel, and it can be further determined based on the well-known Hottel's model (Armstrong, 1978):

$$
I_{t}=I_{b}+I_{d}+I_{r} \text {. }
$$

The unit for $I_{t}$ is defined as $W / \mathrm{m}^{2}$. Notice that $I_{b}$ denotes the beam radiation, $I_{d}$ denotes diffusion, and $I_{r}$ denotes reflection. In estimating the PV power output, $I_{r}$ can be ignored because its contribution to electricity generation is nominal. $I_{d}$ is typically considered as $10 \%$ of $I_{b}$ (Tao et al. 2010).

Given $A_{s}$ and $\eta_{s}$, the power output of a solar PV system is determined by six major factors, including panel direction, tilt angle, calendar day, solar angle (i.e. clock time), latitude, and weather conditions. In this study, we presume the PV panel is directed to the south with its tilt angle equal to the local latitude. Statistically, these set-ups ensure that the panel receives maximum or near-maximum solar irradiance during the course of the year. According to the early work (Villarreal et al. 2012), $I_{t}$ can be expressed in further detail as

$$
I_{t}=I_{c}\left(0.7^{(\cos \varphi)^{-0.678}}\right)\left(\cos \theta+0.1\left(1-\frac{\beta}{\pi}\right)\right),
$$

where, $\varphi$ represents the solar zenith angle which changes from 0 to $\pi / 2$ during the daytime. Other two angles involved in Equation (3) are called PV tilt angle $\beta$ and solar incident angle $\theta$. Note that $\theta$ varies over time during a day. The terrestrial solar irradiance, denoted as $I_{c}$, represents the solar radiation intensity outside the atmosphere. The following equations further defines the models to compute $I_{c}, \theta$, and $\varphi$ can be estimated as

$$
\begin{aligned}
& I_{c}=1370\left(1+0.034 \cos \left(\frac{2 \pi(d-4)}{365}\right)\right) \\
& \cos \theta=\cos \delta \cos (\phi-\beta) \cos \omega+\sin \delta \sin (\phi-\beta)
\end{aligned}
$$




$$
\cos \varphi=\cos \delta \cos \phi \cos \omega+\sin \delta \sin \phi
$$

where,

$$
\delta=0.40928 \sin \left(\frac{2 \pi(d+284)}{365}\right)
$$

Here, $\delta$ is the declination angle, and $\phi$ is the local latitude. $\omega$ is the solar hour angle with $\omega=0$ at 12 p.m. All angles defined in Equations (3) to (7) are in radians (rad). The procedure to estimate the PV power output now can be summarized in five steps:

Step 1: given the date $(d)$ and local clock time (i.e. $\omega$ ), estimate $I_{c}, \delta, \theta$ and $\varphi$ using equations (4)-(7).

Step 2: compute the direct beam using equation (3).

Step 3: compute the total solar irradiance using equation (2).

Step 4: finally compute the PV power output using equation (1).

Step 5: repeat Steps 1-4 to estimate the PV output by changing the clock time and date.

According to equation (1), the PV output power is actually a deterministic value if $d$ and $\omega$ are fixed. $P_{s}$ is stochastic value mainly because of the random weather condition. To incorporate the stochastic nature of the weather, the actual power can be estimated by multiplying Equation (1) by a random variable representing the weather uncertainty. Representative values for this random variable are $0.9,0.7$, and 0.3 for a clear day, a partly cloudy day, and a cloudy day, respectively (Lave et al. May, 2010). The varying weather conditions can be projected from the climate database in (Floudas et al. 1992).

\subsection{Energy Storage System}

The energy storage system (ESS) consists of several interconnected batteries, which allow multiple pathways for current to flow. Ideally for industrial sized ESS low internal resistance is needed for the best efficiency, as well as organization in parallel and series matrices. The purpose of the ESS is to store energy and supply power to the fab when is needed. For further explanation, suppose the Energy Storage Systems has a capacity of size $C$. The charge and discharge rate is expressed as $C_{\text {rate }}$. The time to charge/discharge the battery $T_{c d}$ is give by $T_{c d}=C / C_{\text {rate }} . C_{\text {rates }}$ are provided by the battery manufacturers and are based on slow discharge of 0.1 to $0.25 \mathrm{C}$. Higher rate discharge results in less total current being delivered, and causes internal energy losses and a voltage drop. The battery reaches the low-end voltage cut-off sooner at higher $C_{\text {rates }}$. In theory, the discharging process of a lead-acid battery follows wellknown Peukert's law.

$$
C=I^{k} \Delta t
$$

where, $I$ is discharge current. $\Delta t$ is the discharging time or duration, and $k$ is Peukert constant in a range of [1.1 1.3]. To simulate the charging and discharging process in Matlab, equations (9) and (10) below can be used to approximate the battery state at any given point in time. Let $S(t)$ be the battery energy state at time $t$, then after discharging or charging $\Delta t$, the actual energy in the battery is

$$
\begin{aligned}
& \text { Discharging: } \quad S(t+\Delta t)=\max \left\{0, \quad S(t)-P_{d} \Delta t\right\}, \\
& \text { Charging: } \quad S(t+\Delta t)=\left\{S_{\max }, \quad S(t)+\min \left\{\frac{S_{\max }}{T_{c d}} \Delta t, \quad \eta_{b} E_{c}(\Delta t)\right\}\right\},
\end{aligned}
$$

where, $P_{d}$ is discharging power, $S_{\max }$ is maximum battery capacity, $\eta_{b}$ is the charging efficiency (e.g. 0.7 to 0.85$)$, and $E_{c}(\Delta t)$ is total energy provided in charging.

The battery system plays a dual role in the DG system, either as an energy provider or as an energy consumer depending on the PV output and the hours in a day. There are four different operating cases for the proposed DG system, each elaborated based on the time of the day and the battery's state.

- Case 1: if the PV generates more energy than the demand, the surplus energy will charge the battery or feed to the main grid if the battery is fully charged. This situation usually occurs around the noon time when the PV generation reaches the maximum level. 
- Case 2: if the PV output is less than the load, the battery will provide the difference if available. If the battery is empty, additional energy will be hauled from the main grid through the substation to fill the gap. This situation usually occurs in early morning or later afternoon when the PV output is relatively small.

- Case 3: the battery hauls and stores electricity from the grid during off-peak hours when the utility rate is lower in the night. Since there is no PV generation in the night, the main grid is used to power the wafer fab. In peak hours or daytime, the DG system tries to refrain from using the grid to avoid the high utility rate.

- Case 4: If the aggregate power of PV and battery cannot meet the demand, then the grid will provide the difference. This situation usually occurs during the daytime when the PV output is lower due to the bad weather conditions.

\section{TOTAL DG SYSTEM COSTS}

In spite of the advances of technology, the costs for installing and operating the PV and the ESS are still high. These costs include the one-time capital investment, the operating \& maintenance costs, the utility bills. The direct benefits include the carbon emission reduction and the revenue stream for selling surplus renewable energy. The models used for estimating each of these costs components and benefits are explained below.

\subsection{Equipment Installation Cost}

The energy system under study comprises three types of DG units: PV, substation, and ESS. It should be noted that a substation is generally not included as a part of DG units; however, for convenience of the optimization model we describe it as so. Let $i=1,2$, and 3 be the indexes representing the capacities of the PV system, the substation, and the energy storage system, respectively. The capacity of each resource is treated as a continuous variable. The annualized capital cost of the entire DG system (denoted as $C_{e q}$ ) can be estimated as:

$$
C_{e q}\left(P_{1}^{c}, P_{2}^{c}, P_{3}^{c}\right)=\frac{r(1+r)^{n}}{(1+r)^{n}-1} \sum_{i=1}^{3} a_{i} P_{i}^{c}=\phi(r, n) \sum_{i=1}^{3} a_{i} P_{i}^{c},
$$

where $\phi(r, n)$ is the coefficient computing the cost annuity, $n$ is the number of years necessary to pay off the loan, and $r$ is the interest rate compounded annually. The equipment cost is defined by the system capacity $P_{i}^{c}$, instead of the actual power output, and $a_{i}$ is the cost for installing $1 \mathrm{MW}$ capacity of equipment type $i$ for $i=1,2,3$.

\subsection{Annual Operating and Maintenance Cost}

The annual operating and maintenance (O\&M) cost for the entire DG system is an inclusive sum of all the O\&M costs. According to Villarreal et al. (2012), the costs for maintaining the distribution lines and associated assets are converted and incorporated into the O\&M metrics. The annual O\&M cost for the DG system, denoted as $C_{o m}$, can be expressed as:

$$
C_{\text {om }}\left(P_{1}^{c}, P_{2}^{c}, P_{3}^{c}\right)=\sum_{t=1}^{T} \sum_{i=1}^{3} b_{i} P_{i}(t)
$$

where $b_{i}$ for $i=1,2,3$ are the annual O\&M cost per MWh for the PV, the substation, and the ESS, respectively. $P_{i}(t)$ are random variables representing the instant power at time $t$ (for $t=1,2, \ldots, T$ ). For annual O\&M cost, we typically compute the hourly energy production and hourly O\&M costs, and the annual O\&M cost is obtained by aggregating hourly costs. In that case, $T=8760$ hours per year. 


\subsection{Annual Utility Payment}

Since solar irradiance on the PV behaves stochastically, there is a probability that the renewable power will be unable to consistently meet the load of the wafer fab for a time period of one year. The utility bill includes the costs of hauling the energy from the utility grid. The annual utility cost model for the wafer fab is given as follows:

$$
C_{u p}\left(P_{1}^{c}, P_{2}^{c}, P_{3}^{c}\right)=c \sum_{t=1}^{T}\left(L(t)-P_{1}(t)\right) \operatorname{Pr}\left\{P_{1}(t)<L(t)\right\}
$$

The first item in equation (13) states that the wafer fab pays the utility bill if $P_{1}(t)<L(t)$, with $L(t)$ being the random load at hour $t \in\{1,2, \ldots, 8760\}$. Notice that $c$ is the utility rate in unit of $\$ / \mathrm{MWh}$.

\subsection{Annual Revenue for Selling Surplus Energy}

In the case that the renewable power exceeds the load, the surplus energy will be sold through the process called net metering, which acts as credit in favor of the wafer fab. Let $g$ be the price per MWh for selling the surplus energy, the following model represents the annual revenue made by the wafer fab for selling the surplus energy

$$
R_{p v}\left(P_{1}^{c}, P_{2}^{c}, P_{3}^{c}\right)=g \sum_{t=1}^{T}\left(P_{1}(t)-L(t)\right) \operatorname{Pr}\left\{P_{1}(t) \geq L(t)\right\}
$$

If the utility company and the wafer fab adopt the net metering program, it financially implies that $g=c$. In this study, we assume $g<c$, otherwise the fab always prefers to sell all the renewal energy and use the grid power to support the daily production. The unit of $g$ is in $\$ / M W h$.

\subsection{Lifecycle Costs, LOLP and Carbon Emission Reductions}

By combining all cost items, the annual system lifecycle cost, denoted as $C$, is given as:

$$
C_{s y s}\left(P_{1}^{c}, P_{2}^{c}, P_{3}^{c}\right)=C_{e q}\left(P_{1}^{c}, P_{2}^{c}, P_{3}^{c}\right)+C_{o m}\left(P_{1}^{c}, P_{2}^{c}, P_{3}^{c}\right)+C_{u p}\left(P_{1}^{c}, P_{2}^{c}, P_{3}^{c}\right)-C_{p v}\left(P_{1}^{c}, P_{2}^{c}, P_{3}^{c}\right)
$$

The system planner needs to achieve a balance between the lifecycle cost and the LOLP criterion. The LOLP is given as:

$$
\operatorname{Pr}\left\{\sum_{i=1}^{3} P_{i}(t)>L(t)\right\}>1-\alpha, \text { for } t=1,2, \ldots, 8760
$$

That is, the simulation evaluates the hourly LOLP condition (i.e. power is less than the load in any hour). The annual LOLP is the multiplication of 8760 simulation hours (one simulation year), which in fact was replicated twenty times to count for 20-year lifetime of the PV system. The simulation counts the number of instances in which the LOLP condition was satisfied. Therefore, the annual LOLP is computed by dividing the total count by the number of simulation hours in a year. Every simulation run executed with changing parameters outputted a different, but sometimes similar result. In theory, the hour LOLP criterion should be very small for wafer fabs (e.g. $\alpha=10^{-7}$ ) to mitigate any potential production losses caused by power shortages during the course of a year.

The simulation also calculates the carbon emission avoided based on the PV energy consumed by the fab. In conventional generation, such as coal or other fossil fuel-fired power plant, the amount of $\mathrm{CO}_{2}$ released is around 0.8-0.9 Kg when producing $1 \mathrm{KWh}$ electricity (Zhao 2010). Therefore, we can easily estimate how much carbon footprint is reduced by multiplying the annual renewable energy from the PV with the $\mathrm{CO}_{2}$ rate per $\mathrm{KWh}$.

\section{CASE STUDY}

This section presents a case study demonstrating the design of a cost-effective DG system for wafer fabs located in Austin TX and Dresden Germany, two important cities housing semiconductor manufacturing industries. These facilities have representative loadings equal to the average of $15 \mathrm{MW}$. The virtual fabs 
pull their energy from the DG system for daily operation. The capacity of the solar PV system, the substation, and the ESS module will be determined by using the simulation model.

\subsection{Baseline Costs}

The costs of each equipment options for the DG system under consideration are shown in Table 1. These costs are used for the calculations in Equations 8 and 9. These costs exemplify close figures of the current technology costs based on reports in (Freris and Infield 2008, Yang and Yin 2011) along with authors' direct contact with a battery manufacturer in Austin, TX. Solar PV systems is the most expensive for the initial purchase, however it is the least expensive to maintain.

Table 1: Costs of Virtual DG system

\begin{tabular}{|c|c|c|c|}
\hline $\boldsymbol{i}$ & Equipment Option & $\begin{array}{c}\text { Equipment Cost } \\
(\mathbf{\$} / \mathbf{M W})\end{array}$ & $\begin{array}{c}\text { Annual O\&M Cost } \\
(\mathbf{\$} / \mathbf{M W})\end{array}$ \\
\hline 1 & Substation & 227,500 & 18,750 \\
\hline 2 & Solar PV & $5,000,000$ & 6,000 \\
\hline 3 & Energy Storage System & $1,400,000$ & 200,000 \\
\hline
\end{tabular}

The utility rate for selling and purchasing energy was set at $\$ 100 / \mathrm{MWh}$, regardless of the location of the fab. These costs figures are used in Equations 10 and 11. It is also assumed that there is typically a 4\% increment compounded annually on such utility rates.

\subsection{Design of Experiments}

A general factorial experiment was designed, conducted and analyzed in order to understand how the virtual DG system reacted to different system configurations and different fab locations. The design of experiment (DOE) comprises 3 factors including the PV capacity penetration (Factor A), the ESS capacity (Factor B), and the location (Factor C). Each factor has varying numbers of factor levels, requiring a total of 24 unique combinations. The responses of this experiment, i.e. the system lifecycle cost, the LOLP and the carbon emissions, were analyzed for each scenario. The general factorial design is summarized in Table 2 .

Table 2: Summary of experimental factors and factor levels

\begin{tabular}{|c|c|c|c|c|c|}
\hline Factors & Factor Name & Level 1 & Level 2 & Level 3 & Level 4 \\
\hline A & PV capacity penetration & $0 \%$ & $25 \%$ & $50 \%$ & $100 \%$ \\
\hline B & ESS capacity & 0 hours & 6 hours & 12 hours & None \\
\hline C & Location & Dresden, Germany & Austin, TX & None & None \\
\hline
\end{tabular}

The description of these factors is as follows:

- PV capacity penetration: The percentage of the load that the PV would supply to the wafer fab. Suppose the wafer fab had a load of $15 \mathrm{MWh}$, hence a $7.5 \mathrm{MWh}$ would be provided by the PV at the $50 \%$ capacity penetration level.

- ESS capacity: The amount of hours that the ESS provides reliable power to the wafer fab.

- Location: This factor describes two critical locations housing wafer fabs (i.e. Austin TX and Dresden, Germany. Corresponding geographical and weather data are shown in Table 3. 
Table 3: Geographical and weather data for Dresden Germany and Austin Texas.

\begin{tabular}{|c|c|c|c|c|}
\hline \multirow{2}{*}{ Location } & Latitude & \multicolumn{3}{|c|}{ Weather (Number of Days) } \\
\cline { 2 - 5 } & (Degrees) & Sunny & Partly Cloudy & Cloudy \\
\hline Austin, Texas & 30.27 & 115 & 114 & 136 \\
\hline Dresden, Germany & 51.05 & 68 & 188 & 109 \\
\hline
\end{tabular}

\subsection{Discussion of Results}

As shown in Table 4, the analysis of variances (ANOVA) for the system lifecycle cost indicates that all main factors were significant at a significance level of 0.05. The factor interactions PV penetration-ESS Capacity (AB), PV penetration-Location (AC), ESS capacity-Location (BC) were also significant at a significance level of 0.10 .

Table 4: ANOVA for the lifecycle cost of the proposed DG-based system.

\begin{tabular}{cccccc} 
Source & DF & Sum of Squares & Mean Square & F-Value & P-Value \\
A & 3 & $3.61 \mathrm{E}+13$ & $1.20 \mathrm{E}+13$ & 736.17 & 0.0000 \\
B & 2 & $2.25 \mathrm{E}+15$ & $1.12 \mathrm{E}+15$ & 68678.4 & 0.0000 \\
C & 1 & $3.82 \mathrm{E}+11$ & $3.82 \mathrm{E}+11$ & 23.37 & 0.0030 \\
$\mathrm{AB}$ & 6 & $7.25 \mathrm{E}+12$ & $1.21 \mathrm{E}+12$ & 73.92 & 0.0000 \\
$\mathrm{AC}$ & 3 & $2.25 \mathrm{E}+11$ & 75119680655 & 4.59 & 0.0540 \\
BC & 2 & $1.30 \mathrm{E}+11$ & 64897431264 & 3.97 & 0.0800 \\
Error & 6 & 98139433574 & 16356572262 & & \\
Total & 23 & $2.29090 \mathrm{E}+15$ & & & \\
& \multicolumn{5}{c}{$\mathrm{R}-\mathrm{Sq}=100 \%$ Adj R-Sq=99.98\% }
\end{tabular}

In general, simulation results show slightly higher (but statistically significant) lifecycle costs for the Dresden fab in relation to the lifecycle costs of the Austin fab. These results are expected since there are more sunny and partly cloudy days in Texas than in Germany, thus there is more renewable energy through by the PV system in the Austin fab. The analysis presented hereafter represents the scenario for the Austin fab, but the reader should note that the trends should be similar to those observed in the Dresden fab.

Figures 2-4 show the lifecycle costs, the LOLP, and the carbon emissions, respectively, for different combinations of solar PV penetrations and ESS capacities. The baseline system, i.e. the fab without the PV and ESS technology, incurs in a lifecycle cost of \$23.4 million per year, with an annual LOLP equal to 0.001 . As the solar PV penetration reaches $100 \%$, there is an increase in the lifecycle costs of approximately $\$ 1.4$ million per year, to reach total costs of $\$ 24.8$ million. In this configuration, the LOLP decreases significantly to 0.0005 and the carbon emissions reduction is 15,600 tons per year. Such increase in costs is nominal if one takes into the consideration of the significant reductions in carbon emissions and the power reliability improvements.

Figure 2 also shows that the lifecycle costs increases when an ESS is available. Clearly, the lifecycle costs increases as there is higher ESS capacity. This is largely due to the fact that the equipment cost for ESS is relatively high coupled with the expensive O\&M cost (see Table 1). For instance, if the wafer fab chooses to implement the 12-hour ESS technology, the total system cost would be $\$ 45$ million, almost twice of the baseline system cost. Given the current cost condition of ESS, it might be financially more affordable if one deploys a small scale ESS platform (such as one hour) to mitigate the risks of transient power outrage incidents. 
Sanders, Lopez, Guzman, Jin, and Jimenez

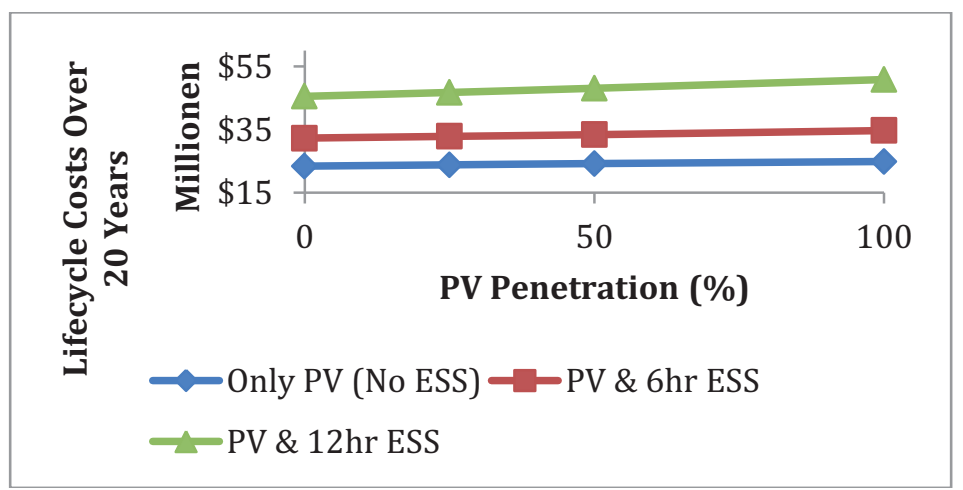

Figure 2: Lifecycle costs for several PV penetrations and ESS capacities.

Figure 3 shows the annual LOLP under various levels of PV penetration and ESS. A general observation is that LOLP decreases with the PV penetration and the ESS capacity. However, the relationship is not strictly linear. For instance, even without ESS, the LOLP decreases by nearly $50 \%$ when the PV capacity is $50 \%$ of the mean load. After that, the trend slows down and level off. On the other hand, with zero PV, the LOLP decreases to 0.0008 when an 6-hour capacity ESS is used; this LOLP decreases even more when a 12-hour capacity ESS is used. However, the difference in the LOLP is smaller as there is higher solar PV penetration. In fact, such difference is practically insignificant at $100 \% \mathrm{PV}$ penetration.

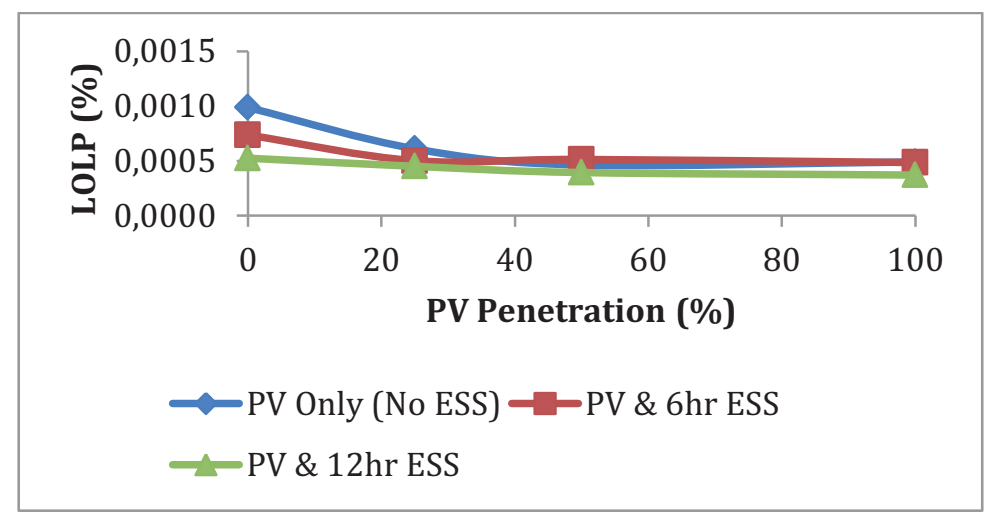

Figure 3: LOLP for several PV penetrations and ESS capacities.

Figure 4 shows the amount of carbon avoided at different PV and ESS penetration levels. There is an expected reduction in the tons of $\mathrm{CO}_{2}$ emissions realized with the penetration of the solar PV system. The reductions in the $\mathrm{CO}_{2}$ emissions are even higher when there is support of the ESS. The ESS capacity did not have a significant effect on the amount of $\mathrm{CO}_{2}$ emission reductions. This is largely due to the fact that the function of the ESS is not to mitigate the carbon footprint, rather it mitigates the risks of power outage by providing energy backup.

\section{CONCLUSION}

In this paper, a DG system featuring solar PV panels, an energy storage system, a substation, and a net metering module is proposed. The DG system is capable of enhancing the reliability of the energy for large industry consumers such as wafer fabs. Most importantly, the DG system significantly reduces the carbon footprint through the direct integration of renewable energy resources. Hence it guarantees a longterm manufacturing sustainability. A simulation model developed in Matlab was used for assessing the system reliability and the cost performance. Quantitative comparisons were made for two wafer fabs located in Austin TX, USA, and Dresden Germany. 


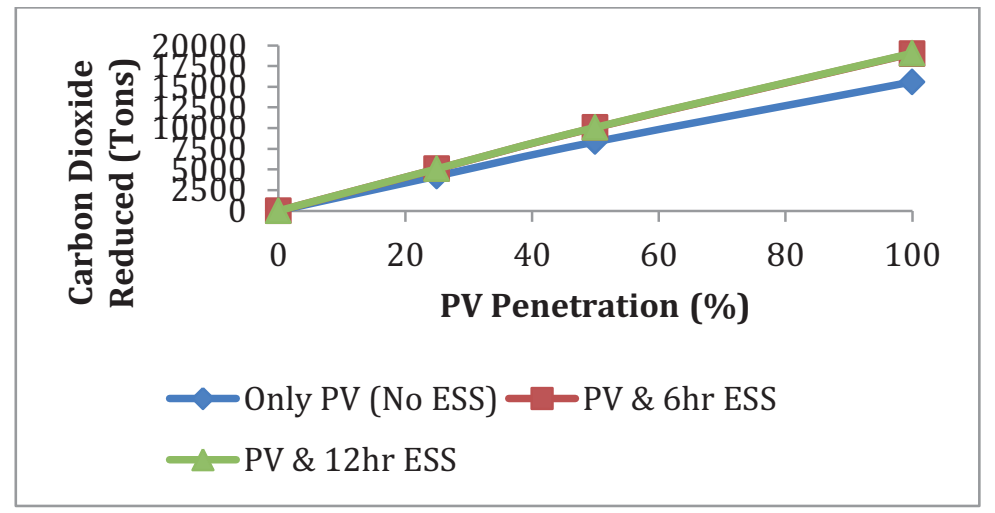

Figure 4: Reduction of Carbon emissions for several PV penetrations and ESS capacities.

There are at least four insights gained from the study: (1) The amount of carbon emissions that was avoided is roughly 16,000 tons per year, and the lowest LOLP approaches to 0.0004 when the injected PV system capacity is equal to the mean load. (2) Given the current cost condition, the DG system cost increases as more renewable energy and ESS technology is used. However the incremental cost of ESS is much more pronounced than the PV; (3) As there is higher PV penetration into the DG system, the LOLP shows a decreasing trend. Furthermore, the LOLP decreases more aggressively by using a DG system and a ESS system; and (4) The design and cost model can be appropriately extended to other industry users. Future work includes the integration of other types of renewable technologies and performing quantitative comparisons in terms of reliability, cost, and carbon emissions. Another line of research is to combine the energy conservation with the DG technology to manage the energy supply and consumption of wafer fabs.

\section{REFERENCES}

Armstrong, P. 1978. "Extension of The Hottel-Whillier Equation to Multi-Stage Collector Systems ." Accessed May 29, 2012. http://web.mit.edu/parmstr/www/pubs/xHW2m5z.pdf.

Floudas C., and P. Pardalos. 1992. Recent Advances in Global Optimization. Princeton, NJ: Princeton University Press.

Freris L., D. Infield. 2008. Renewable Energy in Power System. 1st Ed., Chichester, West Sussex, UK: Wiley \& Sons, Inc.

Hu, S. and Y. Chuah. 2003. "Power Consumption of Semiconductor Fabs in Taiwan." Energy 28: 895907.

International Technology Roadmap of Semiconductors (ITRS). 2011. Environmental, Safety and Health Chapter. [Online]. Available http://www.itrs.net

International SEMATECH Manufacturing Initiative (ISMI). 2005. "ISMI Study Finds Costs Savings Potential in Fab Energy Reduction". [Online]. http://www.sematech.org.

Jones, G.W. and B.H. Chowdhury. 2008. "Distribution System Operation and Planning in the Presence of Distributed Generation Technology." IEEE/PES Transmission and Distribution Conference and Exposition. pp. 1-8.

LaMonica, M. 2010. "Xtreme Power Raises Cash for Renewable-Energy Storage." CNET. Accessed May 30, 2012. http://news.cnet.com/8301-11128_3-20011751-54.html.

Lave, M., and J. Kleissl. 2010. "Optimum Fixed Orientations and Benefits of Tracking for Capturing Solar Radiation in the Continental United States". Accessed May 4, 2012. http://www.sciencedirect.com/science/article/pii/S0960148110003964.

Taboada H., Z. Xiong, T. Jin, and J. Jimenez. 2012. "Exploring a Solar Photovoltaic-Based Energy Solution for Green Manufacturing Environment," In Proceedings of the IEEE Conference on Automation Science \& Engineering: accepted. 
Tao, C., S. Duan, and C. Chen. 2010. "Forecasting Power Output for Grid-connected Photovoltaic Power System Without Using Solar Radiation Measurement." In Proceedings of the 2nd IEEE International Symposium on Power Electronics for Distributed Generation Systems. pp. 773-777.

Texas Instruments. 2010. "RFAB: Green Design” [Online]. Available: http://ww.ti.com.

Ton, D., G. Peek, C. Hanley, and Boyes, J. 2008. "Solar Energy Grid Integration Systems-Energy Storage." Technical Report. Available www1.eere.energy.gov.

Villarreal, S., J. Jimenez, T. Jin, and M. Cabrera-Rios. 2012. "Designing a Sustainable and Distributed Generation System for Semiconductor Wafer Fabs", IEEE Transactions on Automation Science and Engineering, In Press.

Yang D., H. Yin. 2011. "Energy Conversion Efficiency of a Novel Hybrid Solar System for Photovoltaic, Thermoelectric, and Heat Utilization". IEEE Transactions on Energy Conversion, 26(2): pp. 662-670.

Zhao J. 2010. "Greenhouse Gas Abatement Analysis of the Energy Saving Retrofit in Pulverized Coal Power Plants," In Proceedings of the IEEE Power and Energy Engineering Conference (APPEEC), pp. 1-4.

\section{AUTHOR BIOGRAPHIES}

LEANN SANDERS received her B.S. in Industrial Engineering at the Texas State University-San Marcos. She is currently a Damage Prevention Engineer at Enterprise Products. Her research interests are in supply chain management, six sigma, and reliability. Her email is leann.sanders.90@gmail.com.

STEPHANIE LOPEZ received her B.S. in Industrial Engineering at the Texas State University-San Marcos. Her research interests are in supply chain management, quality assurance, and operations research. Her email isss1552@txstate.edu.

GREGORY GUZMAN received his B.S. in Industrial Engineering at the Texas State University-San Marcos. He is currently working at Toyota Motor Manufacturing Texas (TMMT) in San Antonio, TX. He is mainly interested in applications of operations research, lean manufacturing, and supply chain management. His email address is gg1137@txstate.edu.

JESUS JIMENEZ is an Assistant Professor in the Ingram School of Engineering at Texas State University. He received his B.S. and M.S. in Industrial Engineering from The University of Texas at El Paso, and his Ph.D. in Industrial Engineering from Arizona State University. His research interests are in modeling and analysis of manufacturing systems; next generation factories and automated material handling systems (AMHS); discrete-event and agent-based simulation; design of simulation experiments; sustainable lean manufacturing; and distributed energy generation systems using alternative sources of energy. His email address is jesus.jimenez@txstate.edu.

TONGDAN JIN is an Assistant Professor in the Ingram School of Engineering at Texas State University. Prior to the academia, he held a reliability engineer position for five years at Teradyne Inc. He obtained the Ph.D. in Industrial Engineering and MS in Electrical Engineering from Rutgers University. His BS in Electrical Automation is from Northwest Institute of Light Industry, China. His research focuses on reliability modeling and optimization, and distributed generation planning. His email address is tj17@txstate.edu. 